\title{
Pro re nata prescribing and administration for neuropsychiatric symptoms and pain in long-term care residents with dementia and memory problems: a cross-sectional study
}

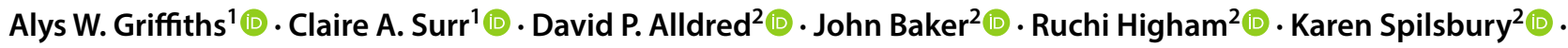 \\ Carl A. Thompson ${ }^{2}$ (1)
}

Received: 1 January 2019 / Accepted: 10 July 2019 / Published online: 24 July 2019

(c) The Author(s) 2019

\begin{abstract}
Background Prescribing, dispensing and administering pro re nata (PRN; as needed or necessary, as determined by an individual) medicines to people with intermittent or short-term conditions is a potential area for medication errors and inappropriate prescribing and administration. In people with dementia, regular PRN medicines use can demonstrate good practice when appropriate or poor in situations where their use is not recommended. However, the frequency of PRN prescription and administration within long-term care settings (care homes) for people with dementia is largely unknown. A limited number of studies worldwide suggest variation between countries. Objective To describe the prescription and administration rates of PRN medicines for people with dementia in UK care homes. Setting Fifty UK care homes. Method Medication details were collected from review of residents' medicines records within the care home for the previous month. Main outcome measure Prescription and administration of PRN medicines for the treatment of behaviours associated with neuropsychiatric symptoms and pain. Results The most commonly prescribed PRN medicines were analgesics (35.3\%), although lower levels of PRN prescription were observed compared to recent studies. The percentage of residents receiving PRN administrations varied, with $20 \%$ for antipsychotics, $50 \%$ for benzodiazepines, $59 \%$ for analgesics, and $85.7 \%$ for nonbenzodiazepine hypnotics being administered. Conclusion Further research is needed to understand the decision making in PRN prescription and administration within long-term care. The prescribing of potentially inappropriate medicines remains a problem in long-term care settings and pharmacists have a key role in reducing inappropriate polypharmacy by undertaking medication reviews that consider both regular and PRN medicines.
\end{abstract}

Keywords Analgesic $\cdot$ Antipsychotics $\cdot$ Dementia $\cdot$ Long-term care $\cdot$ Neuropsychiatric symptoms $\cdot$ Pain $\cdot$ Pro re nata $\cdot$ United Kingdom

\section{Impact on practice}

- There are inconsistencies in practice for people living with dementia and memory problems in care homes, and regular medication reviews are required.

Alys W. Griffiths

alys.griffiths@leedsbeckett.ac.uk

1 Centre for Dementia Research, School of Health and Community Studies, Leeds Beckett University, City Campus, Leeds LS1 3HE, UK

2 School of Healthcare, Faculty of Medicine and Health, University of Leeds, Leeds LS2 9JT, UK
- Non-pharmacological alternatives should be considered for the management of neuropsychological symptoms for people living with dementia and memory problems.

- Particular attention should be given to ensure appropriate antipsychotic prescription for people with dementia and memory problems in care homes. Antipsychotics should only be used where absolutely necessary, and only in the short term.

\section{Introduction}

Dementia affects approximately 47 million people worldwide, and this is projected to rise [1]. Around 20-40\% of people with dementia live in long-term care [2, 3]. 
Multimorbidity (having more than one long term condition) [4] and thus polypharmacy (taking multiple medicines; often defined as $\geq 4$ medicines [5]) is highly prevalent and concerning in long-term care, with $91 \%$ of long-term care residents taking 5+ medicines [5]. A study conducted in England suggested that risks of polypharmacy include multiple side effects, increased risk of preventable hospitalisations, impaired quality of life, increased likelihood of interactions between medicines [4] and higher risks of medication errors, which are common in this population [6, 7]. In addition, inappropriate (over or under) prescribing, is commonplace [8] with implications for health and well-being and associated cost burden to the healthcare system. On average, $50 \%$ (range 24-80\%) of people living in long-term care receive at least one inappropriate medicine and up to $30 \%$ of residents with advanced dementia are prescribed medicines classified as 'never appropriate' for this population [9]. Therefore, understanding the prescription and administration of medicines for residents in long-term care is a clinical and policy imperative.

\section{PRN medicines in long-term care}

Prescribing, dispensing and administering pro re nata (PRN; as needed or necessary, as determined by an individual) medicines to people with intermittent or short-term conditions is a potential area for medication errors and inappropriate prescribing/administration. PRN medicines are given when an individual requires them, rather than as a regular daily dose or at specific times e.g. during a medication round [10]. Long-term care residents with dementia who may have impaired communication rely on staff making accurate and timely judgements of need for administration of PRN medicines. For example, those with impaired communication or who have difficulties taking medicines have been noted to receive less PRN medicines [11]. As a result, guidelines have been developed aimed at improving appropriate assessment and administration of PRN medicines in long-term care settings $[12,13]$.

Alongside warranted variations in PRN administration between residents, unwarranted variations between longterm care settings exist, suggesting PRN use may not be based on individual resident needs, but organisation level factors, such as staffing levels and care home size [11, 14] and staff confidence or knowledge to make judgments about the necessity for PRN medicine administration [15]. The absence of clear instructions for staff on how and when to administer medicines increases the likelihood of adverse events or errors [12]. Therefore, PRN medicines administration may be a signal of underlying care culture and quality and a risk factor in poorer quality care settings.

In people with dementia, regular PRN medicines use can demonstrate good practice when appropriate (e.g.
PRN administration of appropriate analgesics may indicate effective assessment and management of acute or intermittent pain) or poor practice (e.g. PRN administration of antipsychotics may indicate use as a first rather than last resort for managing agitation). This is of concern given the increased risks of these drugs for falls, stroke and death [16] and their recommendation for use only in the short term, if closely monitored and after all psychosocial approaches have been exhausted [17]. Frequent administration of PRN medicines such as pain relief however, may indicate the need for a medication review as a PRN prescription may be inappropriate. For example, antipsychotics should be limited to residents who are severely distressed or at risk of harming themselves or others, and where non-pharmacological interventions have failed. Whilst antipsychotics have proven modest efficacy, side effects can be disabling and they increase the risk of cognitive decline, stroke and death [18]. Likewise the use of certain non-benzodiazepine hypnotics known as $\mathrm{Z}$ drugs has been found to increase of bone fractures and death [19]. Therefore prescription and administration of medicines such as anti-psychotics, benzodiazepines, nonbenzodiazepines, hypnotics and analgesia to people with dementia are of particular interest as they present potential high risks for well-being, quality of life and safety if administered incorrectly or not according to need.

However, the frequency of PRN prescription and administration within long-term care settings (care homes) is largely unknown. A limited number of studies worldwide suggest variation between countries. PRN prescription rates in care homes range from $91 \%$ in the USA [20] and $75 \%$ in Germany [21] to just $31 \%$ in Norway [22]. Significant within-country variations also exist: three studies conducted in Australian long-term care settings found overall PRN prescription rates of 94\% [23], 84\% [11] and 7\% [24]. Other studies have examined PRN medicine prescribing on a specific drug type basis. For example, the frequency of antipsychotic PRN prescription was $24.5 \%$ in a Canadian study [25], 23\% in an Australian study [26], and 37\% [27] and $15 \%$ [28] in two German studies. Analgesic prescribing on a PRN basis ranges from $40 \%$ in Germany [29], $48 \%$ in the USA [30], and $72 \%$ in Norway [31]. Where reported, the most commonly prescribed PRN medicines are analgesics [20, 21, 23, 32, 33] or anxiolytics/hypnotics [24].

Administration levels also vary; one US study reported administration rates of $30 \%$ over 7 days, while two Australian studies reported rates of 54\% [11] and 28\% [23]. Individual medication-type PRN administrations also varied: administrations of analgesia were $30 \%$ in the USA [20] but only $12 \%$ in Norway [31]. Antipsychotic PRN administration rates are generally low. A Canadian study reported only 2.1 PRN administrations on average per resident per month, with most residents receiving no administrations [25]. In 
an Australian study, $11 \%$ of residents received at least one administration in a month [26], whilst in Germany this figure was just 6\% [28].

Within the existing literature, two studies were specifically conducted with people living with dementia [20, 24] and dementia prevalence within the remaining samples ranged from 54 to $98.5 \%$ [26, 31]. Where this was examined those with a PRN prescription were more likely to have dementia ([28], 61 vs 39\% [34]). However, one study [33] found no difference in the likelihood of PRN prescription in residents with and without dementia. Therefore, little is known about the prescribing or administration of PRN medicines to people living with dementia in UK care homes.

In the present study, we were interested in the clinically significant class of PRN medicines related to the management of neuropsychiatric symptoms and pain, which if not managed can lead to neuropsychiatric symptoms [35]. Pain assessment and management for people with dementia is frequently suboptimal [29]. Despite known risks, and evidence suggesting widespread prescription but variable degrees of administration of PRN medicines, there is very limited understanding of PRN medication use in care homes for people living with dementia [36].

\section{Aim of the study}

We aimed to provide the first reported data on the rates of prescription and administration of PRN medicines associated with neuropsychiatric symptoms and pain management for people living with dementia and memory problems in UK long-term care settings (care homes).

\section{Ethics approval}

Ethical approval for the DCM-EPIC trial was gained from the Yorkshire and the Humber Leeds Bradford NHS REC [reference number 13/YH/0016]. Consent from study participants included permission to reanalyse data for research purposes. Ethical approval for this sub-study was granted by Leeds Beckett University Research Ethics Committee.

\section{Method}

Data analysed in this paper was collected as part of the DCM-EPIC trial, a UK randomised controlled trial in care homes. The trial aimed to establish the effectiveness of a person-centred intervention for the quality of life of people living with dementia or memory problems. Baseline data (collected from May 2014-December 2015) on prescribed and administered medication were analysed for this paper.

\section{Participants}

Participants were recruited from 50 care homes in the United Kingdom. Residents with dementia diagnoses or memory problems (i.e. without a confirmed dementia diagnosis) were eligible to participate. Residents formally admitted to an end of life care pathway or who only resided semi-permanently were ineligible.

\section{Procedure}

Care homes were selected by listing all potentially eligible care homes across the three recruitment areas (West Yorkshire, Oxfordshire and South London) using publicly available data. They were then randomly ordered within postcode area/boroughs and the first 10-12 listed care homes approached from one post-code/borough in each hub. This method rotated across each postcode/borough until sufficient homes were recruited. Approach was initially made by post, followed by a researcher phone call. Eligibility was confirmed for any homes potentially interested in participation ahead of consent. Care homes were recruited randomly, stratified by postcode, size, and type. Homes subject to regulatory enforcement or who were deemed 'inadequate' by the UK quality regulator (the Care Quality Commission) were ineligible to participate.

Medication details were collected from residents' medicine administration records for the previous month, held within their care home. Prescription of medicines relevant to the management of neuropsychiatric symptoms associated with dementia, physical and psychological health problems (e.g. antipsychotic, benzodiazepine, mood stabiliser) and pain (analgesic) and frequency of administration of these if prescribed on a PRN basis, was recorded on a standardised form by researchers. Demographic data including comorbidities was collected from resident care records.

Additionally, information about symptoms of agitation was collected using the Cohen-Mansfield Agitation Inventory (CMAI [37]), which measures 29 behaviours typically associated with agitation/aggression. Staff members identified the frequency of 29 behaviours during the previous 2 weeks, rated on a seven-point Likert scale (1-7) ranging from "never" to "several times an hour". This measure shows moderate concurrent validity with scores on the Neuropsychiatric Inventory-Nursing Home version Agitation subscale $(r=.52[38])$. 


\section{Statistical analysis}

We calculated descriptive data (counts and means) by resident and care home. To explore our hypothesis that individual care home approach to medicines use were related

Table 1 Participant demographics

\begin{tabular}{lc}
\hline Characteristics & \\
Age at registration (years) M (SD) & $85.6(7.64)$ \\
Gender & \\
Female & $536(73.8 \%)$ \\
Male & $190(26.2 \%)$ \\
Length of stay in care home (years) M (SD) & $2.3(2.34)$ \\
Ethnicity & \\
White British/European & $702(96.7 \%)$ \\
Other & $24(3.3 \%)$ \\
Funding type & \\
Local authority & $352(48.5 \%)$ \\
Self-funded & $289(39.8 \%)$ \\
Local authority and self-funded & $34(4.7 \%)$ \\
Continuing healthcare & $48(6.6 \%)$ \\
Missing & $3(.4 \%)$ \\
Dementia severity (measured by functional assessment staging tool) \\
$1-3$ & $6(1 \%)$ \\
4 & $95(13.6 \%)$ \\
5 & $74(10.6 \%)$ \\
6 & $380(54.5 \%)$ \\
7 & $142(20.4 \%)$ \\
Missing & $29(3.9 \%)$ \\
\hline
\end{tabular}

to rates of PRN administration, we calculated Pearson's correlation coefficients using SPSS version 25.

\section{Results}

\section{Demographic characteristics}

A total of 728 participants were recruited from 50 care homes ( 31 residential or nursing home, 19 dementia care specialist home). Care homes provided care for an average of 31.8 residents, with an average of $77.7 \%$ of residents having dementia (see Table 1 for participant demographics). Participants had, on average, two comorbidities alongside dementia (range 0-14). Selected comorbidities often associated with PRN prescriptions included depression $(\mathrm{n}=117,16.1 \%)$, anxiety $(n=57,7.9 \%)$, psychosis $(n=40,5.5 \%)$, sleep disturbance $(\mathrm{n}=13,1.8 \%)$, and delirium $(\mathrm{n}=5, .7 \%)$. Demographic data were missing for two participants who were not included in analyses, providing a total of 726 participants.

\section{Medication use}

The total number of regular medicines prescribed per resident ranged from 0 to 28 (mean $=8.68, \mathrm{SD}=4.14)$ with $0-3$ on a PRN basis $(\mathrm{Mean}=.4, \mathrm{SD}=.60)$. Eight residents $(.1 \%)$ were not prescribed any medicines. The total number of medication prescriptions was 6266, of these 5949 (95.0\%) were regularly prescribed and $317(5.0 \%)$ prescribed on a PRN basis. The prevalence of regularly and PRN prescribed medicines is shown in Table 2, stratified by gender, age and
Table 2 Pro re nata (PRN) prescribing for residents in care homes stratified by demographic characteristics $(\mathrm{N}=726)$

\begin{tabular}{lllll}
\hline & No PRN medicine & 1 PRN medicine & 2 PRN medicines & 3 PRN medicines \\
\hline $\begin{array}{l}\text { Age } \\
<70\end{array}$ & $21(70)$ & $7(23)$ & & \\
$70-79$ & $86(64)$ & $37(28)$ & $2(7)$ & - \\
$80-89$ & $232(67)$ & $93(27)$ & $9(7)$ & $2(1)$ \\
$\geq 90$ & $130(61)$ & $68(32)$ & $19(5)$ & $4(1)$ \\
All & $469(65)$ & $205(28)$ & $44(6)$ & $2(<1)$ \\
Gender & & & & $8(1)$ \\
Female & $332(62)$ & $182(34)$ & $20(4)$ & $2(<1)$ \\
Male & $137(72)$ & $44(23)$ & $6(3)$ & $3(2)$ \\
Regular prescriptions & & & \\
M (SD) range & $8.03(4.11) 0-28$ & $8.72(3.92) 1-23$ & $8.81(3.69) 3-17$ & $8.60(5.08) 4-16$ \\
$0-4$ & $92(69)$ & $37(29)$ & $2(1)$ & $2(1)$ \\
$5-9$ & $230(66)$ & $102(30)$ & $14(4)$ & $2(<1)$ \\
$\geq 10$ & $147(60)$ & $87(35)$ & $10(4)$ & $2(1)$ \\
\hline
\end{tabular}

All numbers provided as N (\% of category) unless otherwise specified 
Table 3 Prevalence of prescribed and administered regular and PRN medicines $(\mathrm{N}=726)$

\begin{tabular}{|c|c|c|c|c|}
\hline Medication & $\begin{array}{l}\mathrm{N} \text { residents }(\%) \\
\text { prescribed }\end{array}$ & $\begin{array}{l}\mathrm{N} \text { medicines } \\
\text { prescribed }\end{array}$ & $\begin{array}{l}\mathrm{N}(\%) \text { medicines adminis- } \\
\text { tered of prescribed }\end{array}$ & $\begin{array}{l}\text { Number of administrations per resident of those } \\
\text { administered at least once over a month [M (SD) } \\
\text { range] }\end{array}$ \\
\hline \multicolumn{5}{|c|}{ Antipsychotic } \\
\hline Regular & $93(12.8)$ & 96 & - & - \\
\hline PRN & $10(1.4)$ & 10 & $2(20)$ & $4.14(8.30) 0-22$ \\
\hline \multicolumn{5}{|c|}{ Benzodiazepine } \\
\hline Regular & $43(6.0)$ & 47 & - & - \\
\hline PRN & $38(5.4)$ & 39 & $19(50)$ & $18.62(35.84) 0-137$ \\
\hline \multicolumn{5}{|c|}{ Non-benzodiazepine hypnotic } \\
\hline Regular & $40(5.5)$ & 40 & - & - \\
\hline PRN & $6(1.0)$ & 6 & $5(85.7)$ & 28.83 (47.30) $0-123$ \\
\hline \multicolumn{5}{|c|}{ Antidepressant } \\
\hline Regular & $268(37.0)$ & 299 & - & - \\
\hline PRN & $3(.4)$ & 3 & $3(100)$ & $31(41.87) 2-79$ \\
\hline \multicolumn{5}{|c|}{ Cognition enhancing medicines } \\
\hline Regular & $171(23.6)$ & 177 & - & - \\
\hline \multicolumn{5}{|c|}{ Anticonvulsants } \\
\hline Regular & $35(4.8)$ & 40 & - & - \\
\hline \multicolumn{5}{|c|}{ Mood stabilisers } \\
\hline Regular & $3(.4)$ & 3 & - & - \\
\hline \multicolumn{5}{|l|}{ Analgesic } \\
\hline Regular & $356(50.1)$ & 468 & - & - \\
\hline PRN & $256(35.3)$ & 259 & $151(58.3)$ & $25.14(36.43) 0-122$ \\
\hline
\end{tabular}

regular medication prescription, in line with previous reporting $[21,22]$.

The most frequently prescribed PRN medication were analgesics with over a third of participants $(35.3 \%)$ prescribed them (see Table 3 for breakdown of type of medication prescribed). All other PRN prescriptions were at very low levels, ranging from .4\% for mood stabilisers to $5.4 \%$ for benzodiazepines. The class/individual medicines prescribed and administered can be seen in Table 4.

\section{Correlation analyses}

Neither the total number of prescribed medicines $(r=.03$, $p>.05)$, nor the number of PRN medicines administered $(r=.14, p>.05)$ correlated with care home.

Level of agitation (as measured by the CMAI), was associated with total number of PRN prescriptions $(r=.08$, $p<.05)$, but not total number of regular and PRN prescriptions $(r=-.06, p>.05)$.

\section{Discussion}

The current study presented the first evidence on PRN medication prescribing and administration within UK long-term care settings (care homes) for people with dementia. The most commonly prescribed PRN medicines were analgesics, in line with most recent evidence [21]. However, this may not be universally positive as many staff members lack the skills to perform adequate pain assessments, meaning residents do not always receive analgesic medicines when needed [30]. This is particularly important as cognitive impairment is associated with decreased likelihood of receiving PRN analgesics [31]. In addition, continuing potentially inappropriate long-term PRN analgesics without review, for example nonsteroidal anti-inflammatory drugs (NSAIDs), may mask or cause potentially harmful interactions or adverse effects [39, 40]. Regular and PRN NSAIDs can cause peptic ulcer disease, may increase thrombotic risk and impair renal function with the potential for Acute Kidney Injury. NSAIDs also interact with many commonly prescribed medicines, including antihypertensives, antithrombotics, lithium and Selective Serotonin Reuptake Inhibitors [41]. Unfortunately, we did not collect data on the underlying reasons why medications were prescribed (see study 
Table 4 Medicines prescribed by name and type

\begin{tabular}{|c|c|c|c|}
\hline Medication & $\begin{array}{l}\text { Total } \\
\text { medicines } \\
\text { prescribed }\end{array}$ & Regular & PRN \\
\hline Antipsychotic & 106 & 96 & 10 \\
\hline Amisulpride & 6 & 5 & 1 \\
\hline Aripriprazole & 5 & 5 & - \\
\hline Chloropromazine & 1 & 1 & - \\
\hline Flupentixol & 3 & 3 & - \\
\hline Haloperidol & 4 & 4 & 3 \\
\hline Levomepromazine & 2 & - & 2 \\
\hline Olanzapine & 17 & 17 & - \\
\hline Prochlorperazine & 2 & 1 & 1 \\
\hline Quetiapine & 19 & 19 & - \\
\hline Risperidone & 43 & 40 & 2 \\
\hline Benzodiazepine & 86 & 47 & 39 \\
\hline Clonazepam & 2 & 2 & - \\
\hline Diazepam & 24 & 13 & 11 \\
\hline Lorazepam & 46 & 19 & 27 \\
\hline Midazolam & 1 & 1 & - \\
\hline Nitrazepam & 4 & 4 & - \\
\hline Oxazepam & 1 & 1 & - \\
\hline Temazepam & 8 & 7 & 1 \\
\hline Non-benzodiazepine hypnotic & 46 & 40 & 6 \\
\hline Chlormethiazole & 1 & - & 1 \\
\hline Melatonin & 1 & 1 & - \\
\hline Zopiclone & 44 & 39 & 5 \\
\hline Antidepressant & 302 & 299 & 3 \\
\hline Amitriptyline & 18 & 18 & - \\
\hline Citalopram & 88 & 88 & - \\
\hline Dosulepin & 1 & 1 & - \\
\hline Duloxetine & 2 & 2 & - \\
\hline Escitalopram & 2 & 2 & - \\
\hline Fluoxetine & 9 & 9 & - \\
\hline Lofepramine & 3 & 3 & - \\
\hline Mirtazapine & 80 & 80 & - \\
\hline Paroxetine & 2 & 2 & - \\
\hline Sertraline & 26 & 26 & - \\
\hline Trazodone & 61 & 58 & 3 \\
\hline Venlafaxine & 7 & 7 & - \\
\hline Cognition enhancing medicines & 177 & 177 & - \\
\hline Donepezil & 87 & 87 & - \\
\hline Galantamine & 19 & 19 & - \\
\hline Memantine & 55 & 55 & - \\
\hline Rivastigmine & 16 & 16 & - \\
\hline Anticonvulsants & 40 & 40 & - \\
\hline Carbamazepine & 10 & 10 & - \\
\hline Gabapentin & 2 & 2 & - \\
\hline Lamotrigine & 1 & 1 & - \\
\hline Levetiracetam & 7 & 7 & - \\
\hline Phenobarbital & 3 & 3 & - \\
\hline Phenytoin & 2 & 2 & - \\
\hline
\end{tabular}

Table 4 (continued)

\begin{tabular}{lcll}
\hline Medication & $\begin{array}{l}\text { Total } \\
\text { medicines } \\
\text { prescribed }\end{array}$ & Regular & PRN \\
\hline Pregabalin & 1 & 1 & - \\
Sodium valproate & 12 & 12 & - \\
Topiramate & 1 & 1 & - \\
Mood stablisers & 3 & 3 & - \\
Lithium & 3 & 3 & - \\
Analgesic & 724 & 468 & 256 \\
Aspirin & 102 & 101 & 1 \\
Buprenorphine & 21 & 21 & - \\
Co-codamol & 55 & 34 & 21 \\
Codeine & 42 & 27 & 15 \\
Ibuprofen & 23 & 18 & 5 \\
Morphine & 13 & 6 & 7 \\
Paracetamol & 447 & 243 & 204 \\
Tramadol & 9 & 8 & 1 \\
Other & 12 & 10 & 2 \\
\hline
\end{tabular}

limitations). We therefore cannot rule out the possibility that staff behaviours relating to PRN use for people with dementia increase exposure to potentially inappropriate medications with an unfavourable balance of benefits and harms, when compared to alternative treatment options. More research is needed to ascertain the degree to which a diagnosis of dementia modifies the probability of meeting STOPP (Screening Tool of Older Person's Prescriptions) or Beers criteria or not benefiting from START (Screening Tool to Alert doctors to Right Treatment) criteria [39, 40].

Our data was collected after publication of guidance on antipsychotic medication prescribing for people with dementia within the UK [12]. This suggested antipsychotic medication should be used as a last resort, and not longer than 6 weeks at a time. Within our sample, $1.4 \%$ had a prescription for an antipsychotic medication on a PRN basis and $12.7 \%$ on a regular basis. However, we cannot know whether the levels observed are specific to our sample without drawing comparisons to other care home samples within the UK. Only one study has considered both regular and PRN antipsychotic use, where Managers reported that $8 \%$ of residents had a regular and $4 \%$ of residents had a PRN antipsychotic prescription [42], however caution should be exercised in interpreting this self-reported data from managers. The study also did not report how frequently prescribed PRN medications were administered. As our data were crosssectional we do not know how long regular antipsychotic medicines had been prescribed. A low level of PRN antipsychotic prescriptions was reported in a recent Australian study [23], although their seven-day data collection period included only one administration on average, whereas within our sample, there were two administrations across 1 month. 
This may reflect recent increased understanding about the potential harms of antipsychotic administration for people living with dementia [23] or the presence of good practice guidelines for care homes to work with $[12,13]$. Whilst we observed generally low levels of PRN prescriptions and administrations, it is not known whether this is in response to the guidelines, as no evidence exists for the prevalence of PRN prescriptions in the UK before their development.

PRN medication administration varied within the present study. For some categories, such as antipsychotics, only 2 of 10 residents received an administration within the onemonth data collection period. Other categories, such as benzodiazepines and non-benzodiazepine hypnotics, were far more common. For example, 50\% of participants prescribed these on a PRN basis received at least one administration during the month. However, some residents received over 100 administrations of benzodiazepines and non-benzodiazepine hypnotics within the data collection period. Such under and over exploitation of possibilities suggests inappropriate PRN prescriptions for some residents and should trigger the need for a medication review. For example, a regular dose may have been warranted. Additionally, this may indicate a trend of prescribing benzodiazepines and other sedating drugs in place of antipsychotics, given the drivers to reduce the prescription of the latter in people with dementia, which is of concern. In addition to antipsychotics and benzodiazepines, other medicines that were prescribed would be deemed potentially inappropriate, particularly in people with dementia. For example, tricyclic antidepressants, paroxetine and fluoxetine [39, 40]. Future research should explore this as there are clear guidelines regarding the long-term use of benzodiazepines within this population [43]. This is due to issues around dependency, toxicity, cognitive decline, falls and increased sensitivity towards side effects such as delirium $[44,45]$. The needs of long-term care residents should be regularly reviewed to ensure only required medicines are prescribed and administered and that PRN prescriptions remain appropriate [6]. This is particularly important for those with dementia, as individuals with more severe cognitive impairment were less likely to receive pain relief on a PRN basis [20,31] possibly as they struggle to communicate their symptoms [23], or expressions of pain through behaviours such as agitation are attributed as a symptom of dementia [46]. However, in our study, we found that there was a weak but significant relationship between number of PRN prescriptions and scores on an agitation measure. Further research is needed to understand this relationship and how well understood the needs of individuals experiencing agitation are.

Previous research suggests the main predictor of PRN medication is often the care home in which the resident lives [11]. We found the likelihood of being prescribed PRN medicines did not differ by care home. This could be because
PRN prescriptions for some categories (i.e. antipsychotics) were too small to generate significant differences, rather than a lack of differences.

Our research implies that PRN use is lower than anticipated, but the current research base does not allow us to state, with confidence, that this is a genuine shift in expected prescription and administration. Future research should seek to collate the datasets from several large-scale clinical trials that have recently been completed in the UK, to establish whether this pattern of lower prescribing is seen more widely, before establishing whether a general trend towards lower PRN prescriptions for people with dementia is being seen generally.

\section{Strengths and limitations}

This study presented the first examination of PRN medication prescription and administration within UK care homes for people with dementia. Whilst the data are cross-sectional, they provide an overview of current prescribing practices. Although, we do not know whether as dementia progresses, individuals are more likely to receive prescriptions for PRN medicines. Existing evidence suggests that as residents spend longer in care homes, their likelihood of receiving a PRN prescription increases [21]. Future work should seek to examine changes in prescriptions and administrations over time and their association with harms in care homes, such as falls and hospitalisations. Our data only included those falls resulting in hospitalisation. We are unlikely to have captured their true extent, and so analysing this data would have been inappropriate. Furthermore, whilst we have data on frequency of administrations, we do not have dosage or reason for prescription, which limited interpretation of the appropriateness of prescriptions. Heterogeneous data collection and research questions mean drawing comparisons between our findings and those of similar existing studies may be inappropriate.

\section{Conclusion}

For the first time in the UK, this study presented the first evidence of the prescription and administration of PRN medicines for neuropsychiatric symptoms and pain management for people living with dementia. Generally, low levels of prescriptions and even lower levels of administrations were observed for the management of neuropsychiatric symptoms. This could be viewed positively as non-pharmacological treatments for dementia are being encouraged. However, the variation seen in PRN administrations suggests more research is needed to understand UK practices. The prescribing of potentially inappropriate medicines remains 
a problem in long-term care and pharmacists have a key role in reducing inappropriate polypharmacy by undertaking medication reviews that consider both regular and PRN medicines.

Acknowledgements We would like to thank all the care homes, individuals living with dementia or memory problems, their family members and care home staff for taking part in this study and giving freely of their time.

Funding This project was funded by the National Institute for Health Research Health Technology Assessment (NIHR HTA) program (project number 11/15/13). The views and opinions expressed therein are those of the authors and do not necessarily reflect those of the HTA, NIHR, NHS or the Department of Health and Social Care. The funder had no role in study design, methods, recruitment, data acquisition, analysis or preparation of this paper.

Conflicts of interest The authors declare that they have no conflicts of interest.

Open Access This article is distributed under the terms of the Creative Commons Attribution 4.0 International License (http://creativeco mmons.org/licenses/by/4.0/), which permits unrestricted use, distribution, and reproduction in any medium, provided you give appropriate credit to the original author(s) and the source, provide a link to the Creative Commons license, and indicate if changes were made.

\section{References}

1. Livingston G, Sommerlad A, Orgeta V, Costafreda SG, Huntley J, Ames D, et al. Dementia prevention, intervention, and care. The Lancet. 2017;390(10113):2673-734.

2. Khillan R, Lepore M, Ferrell A, Wiener JM. Living arrangements of people with Alzheimer's disease and related dementias: implications for services and supports. 2017. https://pdfs.semanticsc holar.org/77e3/7974d41d5d225079a354b594c39685f0b163.pdf. Accessed 1 Nov 2018.

3. Prince M, Knapp M, Guerchet M, McCrone P, Prina M, ComasHerrera A, et al. Dementia UK update. 2014. https://www.alzhe imers.org.uk/sites/default/files/migrate/downloads/dementia_uk_ update.pdf. Accessed 1 Nov 2018.

4. Mueller C, Molokhia M, Perera G, Veronese N, Stubbs B, Shetty $\mathrm{H}$, et al. Polypharmacy in people with dementia: associations with adverse health outcomes. Exp Gerontol. 2018;106:240-5.

5. Rankin A, Cadogan CA, Patterson SM, Kerse N, Cardwell CR, Bradley MC, et al. Interventions to improve the appropriate use of polypharmacy for older people. Cochrane Database Syst Rev. 2018. https://doi.org/10.1002/14651858.CD008165.pub4.

6. Barber ND, Alldred DP, Raynor DK, Dickinson R, Garfield S, Jesson B, et al. Care homes' use of medicines study: prevalence, causes and potential harm of medication errors in care homes for older people. BMJ Qual Saf. 2009;18(5):341-6.

7. Szczepura A, Wild D, Nelson S. Medication administration errors for older people in long-term residential care. BMC Geriatr. 2011;11(1):82.

8. O'Connor MN, Gallagher P, O'Mahony D. Inappropriate prescribing. Drugs Aging. 2012;29(6):437-52.

9. Storms H, Marquet K, Aertgeerts B, Claes N. Prevalence of inappropriate medication use in residential long-term care facilities for the elderly: a systematic review. Eur J Gen Pract. 2017;23(1):69-77.

10. Centre for Policy on Ageing. Managing and administering medication in care homes for older people. 2014. http://www.cpa.org.uk/ information/reviews/Managing_and_Administering_Medication _in_Care_Homes.pdf. Accessed 1 Nov 2018.

11. Stokes JA, Purdie DM, Roberts MS. Factors influencing PRN medication use in nursing homes. Pharm World Sci. 2004;26(3):148-54.

12. National Institute for Health and Care Excellence. Managing medicines in care homes. 2014. https://www.nice.org.uk/guidance/sc1/ resources/managing-medicines-in-care-homes-pdf-61677133765. Accessed 1 Nov 2018.

13. Australian Pharmaceutical Advisory Council. Guidelines for medication management in residential aged care facilities. 3rd ed. Canberra: Commonwealth of Australia; 2002.

14. Schmidt I, Claesson CB, Westerholm B, Svarstad BL. Resident characteristics and organizational factors influencing the quality of drug use in Swedish nursing homes. Soc Sci Med. 1998;47:961-71.

15. Jessop T, Harrison F, Cations M, Draper B, Chenoweth L, Hilmer $\mathrm{S}$, et al. Halting Antipsychotic Use in Long-Term care (HALT): a single-arm longitudinal study aiming to reduce inappropriate antipsychotic use in long-term care residents with behavioral and psychological symptoms of dementia. Int Psychogeriatr. 2017;29(8):1391-403.

16. Banerjee $\mathrm{S}$. The use of antipsychotic medication for people with dementia: Time for action. A report for the Minister of State for careservices. London, England: Department of Health; 2009.

17. Matlow JN, Bronskill SE, Gruneir A, Bell CM, Stall NM, Herrmann $\mathrm{N}$, et al. Use of medications of questionable benefit at the end of life in nursing home residents with advanced dementia. J Am Geriatr Soc. 2017;65(7):1535-42.

18. Tampi RR, Tampi DJ, Balachandran S, Srinivasan S. Antipsychotic use in dementia: a systematic review of benefits and risks from meta-analyses. Ther Adv Chronic Dis. 2016;7(5):229-45.

19. Fox C, Arthur A, Ballard C, Howard RJ, Maidment ID, Pakpahan E, et al. Beyond antipsychotics: exploring efficacy and harms of z-drugs for sleep disturbance on the progression of key dementia outcomes. Alzheimer's Dement J Alzheimer's Assoc. 2018;14(7):P1072-3.

20. Mezinskis PM, Keller AW, Luggen AS. Assessment of pain in the cognitively impaired older adult in long-term care. Geriatr Nurs. 2004;25(2):107-12.

21. Dörks M, Herget-Rosenthal S, Schmiemann G, Hoffmann F. Polypharmacy and renal failure in nursing home residents: results of the inappropriate medication in patients with renal insufficiency in nursing homes (IMREN) study. Drugs Aging. 2016;33(1):45-51.

22. Fog AF, Kvalvaag G, Engedal K, Straand J. Drug-related problems and changes in drug utilization after medication reviews in nursing homes in Oslo, Norway. Scand J Prim Health Care. 2017;35(4):329-35.

23. Stasinopoulos J, Bell JS, Ryan-Atwood TE, Tan EC, Ilomäki J, Cooper T, et al. Frequency of and factors related to pro re nata (PRN) medication use in aged care services. Res Soc Admin Pharm. 2018;14(10):964-7.

24. Moyle W, El Saifi N, Draper B, Jones C, Beattie E, Shum D, et al. Pharmacotherapy of persons with dementia in long-term care in Australia: a descriptive audit of central nervous system medications. Curr Drug Saf. 2017;12(2):95-102.

25. Hagen B, Esther CA, Ikuta R, Williams RJ, Le Navenec C, Aho M. Antipsychotic drug use in Canadian long-term care facilities: prevalence, and patterns following resident relocation. Int Psychogeriatr. 2005;17(2):179-93. 
26. Brodaty H, Aerts L, Harrison F, Jessop T, Cations M, Chenoweth $\mathrm{L}$, et al. Antipsychotic deprescription for older adults in long-term care: the HALT study. J Am Med Dir Assoc. 2018;19(7):592-600.

27. Allers K, Dörks M, Schmiemann G, Hoffmann F. Antipsychotic drug use in nursing home residents with and without dementia: keep an eye on the pro re nata medication. Int Clin Psychopharmacol. 2017;32(4):213-8.

28. Sonntag A, Matschinger H, Angermeyer MC, Riedel-Heller SG. Does the context matter? Utilization of sedative drugs in nursing homes-a multilevel analysis. Pharmacopsychiatry. 2006;39(04):142-9.

29. Hoffmann F, Schmiemann G. Pain medication in German nursing homes: a whole lot of metamizole. Pharmacoepidemiol Drug Saf. 2016;25(6):646-51.

30. Kayser-Jones JS, Kris AE, Miaskowski CA, Lyons WL, Paul SM. Hospice care in nursing homes: does it contribute to higher quality pain management? The Gerontologist. 2006;46(3):325-33.

31. Nygaard HA, Jarland M. Are nursing home patients with dementia diagnosis at increased risk for inadequate pain treatment? Int $\mathrm{J}$ Geriatr Psychiatry. 2005;20(8):730-7.

32. Arinzon Z, Peisakh A, Zuta A, Berner YN. Drug use in a geriatric long-term care setting. Drugs Aging. 2006;23(2):157-65.

33. Krüger K, Folkestad M, Geitung JT, Eide GE, Grimsmo A. Psychoactive drugs in seven nursing homes. Prim Health Care Res Dev. 2012;13(3):244-54.

34. Hagen BF, Armstrong-Esther C, Quail P, Williams RJ, Norton $\mathrm{P}$, Le Navenec CL, et al. Neuroleptic and benzodiazepine use in long-term care in urban and rural Alberta: characteristics and results of an education intervention to ensure appropriate use. Int Psychogeriatr. 2005;17(4):631-52.

35. van Dalen-Kok AH, Pieper MJ, de Waal MW, Lukas A, Husebo BS, Achterberg WP. Association between pain, neuropsychiatric symptoms, and physical function in dementia: a systematic review and meta-analysis. BMC Geriatr. 2015;15(1):49.

36. Murray LO. The role of the registered nurse managing pro re nata (PRN) medicines in the care home (nursing): a case study of decision-making, medication management and resident involvement. DHRes thesis, University of Hertfordshire. 2016.

37. Cohen-Mansfield J, Billig N. Agitated behaviours in the elderly. I. A conceptual review. J Am Geriatr Soc. 1986;34:711-21.
38. Wood S, Cummings JL, Hsu M-A, Barclay T, Wheatley MV. The use of the neuropsychiatric inventory in nursing home residents. Am J Geriatr Psychiatry. 2000;8:75-83.

39. Fick DM, Semla TP, Steinman M, Beizer J, Brandt N, Dombrowski R, American Geriatrics Society Beers Criteria ${ }^{\circledR}$ Update Expert Panel, et al. American Geriatrics Society 2019 updated AGS Beers Criteria ${ }^{\circledR}$ for potentially inappropriate medication use in older adults. J Am Geriatr Soc. 2019;67(4):674-94.

40. O'Mahony D, O'Sullivan D, Byrne S, O'Connor MN, Ryan C, Gallagher P. STOPP/START criteria for potentially inappropriate prescribing in older people: version 2. Age Ageing. 2015;44(2):213-8.

41. Moore N, Pollack C, Butkerait P. Adverse drug reactions and drug-drug interactions with over-the-counter NSAIDs. Ther Clin Risk Manag. 2015;11:1061-75.

42. Backhouse T, Killett A, Penhale B, Burns D, Gray R. Behavioural and psychological symptoms of dementia and their management in care homes within the East of England: a postal survey. Aging Mental Health. 2014;18(2):187-93.

43. Johnson CF, Frei C, Downes N, McTaggart SA, Akram G. Benzodiazepine and z-hypnotic prescribing for older people in primary care: a cross-sectional population-based study. Br J Gen Pract. 2016;66(647):e410.

44. Airagnes G, Pelissolo A, Lavallée M, Flament M, Limosin F. Benzodiazepine misuse in the elderly: risk factors, consequences, and management. Curr Psychiatry Rep. 2016;18(10):89.

45. Brett J, Murnion B. Management of benzodiazepine misuse and dependence. Aust Prescr. 2015;38(5):152.

46. Lichtner V, Dowding D, Esterhuizen P, Closs SJ, Long AF, Corbett A, et al. Pain assessment for people with dementia: a systematic review of systematic reviews of pain assessment tools. BMC Geriatr. 2014;14(1):138.

Publisher's Note Springer Nature remains neutral with regard to jurisdictional claims in published maps and institutional affiliations. 